06.5

\title{
Влияние ионного облучения на морфологию, элементный и химический состав поверхностных слоев безвольфрамовых твердых сплавов
}

\author{
(C) А.М. Бадамшин ${ }^{1}$, С.Н. Несов ${ }^{1}$, В.С. Ковивчак ${ }^{2}$, С.Н. Поворознюк ${ }^{1}$, В.В. Акимов ${ }^{3}$ \\ ${ }^{1}$ Омский государственный технический университет, Омск, Россия \\ ${ }^{2}$ Омский государственный университет им. Ф.М. Достоевского, Омск, Россия \\ ${ }^{3}$ Сибирский государственный автомобильно-дорожный университет, Омск, Россия \\ E-mail: Artembadamschin@mail.ru
}

Поступило в Редакцию 24 марта 2021 г.

В окончательной редакции 21 апреля 2021 r.

Принято к публикации 30 апреля 2021 г.

\begin{abstract}
Исследовано влияние ионных пучков различной интенсивности и длительности на изменение элементного состава и химического состояния в поверхностных слоях безвольфрамового твердого сплава $50 \% \mathrm{TiC}-50 \% \mathrm{TiNi}$. Методами растровой электронной микроскопии и рентгеновской фотоэлектронной спектроскопии проведен анализ морфологии и состава поверхностного слоя твердого сплава после воздействия непрерывного и импульсного ионных пучков. Показано, что облучение непрерывным ионным пучком вызывает дополнительное окисление поверхности твердого сплава. Установлено, что воздействие импульсного ионного пучка приводит к формированию карбидов титана в интерметаллидной связке твердого сплава, а также к снижению в ней доли оксидов металлов.
\end{abstract}

Ключевые слова: твердые сплавы, карбид титана, никелид титана, импульсный ионный пучок, непрерывный ионный пучок.

DOI: 10.21883/PJTF.2021.15.51228.18783

Безвольфрамовые твердые сплавы (БВТС), прежде всего на основе карбида титана с различными связующими фазами (Ni, Mo, TiNi), являются недорогой альтернативой традиционным твердым сплавам на основе карбида вольфрама. Перспективным способом улучшения физико-механических свойств твердых сплавов является ионно-лучевая обработка (ИЛО) [1]. Модифицирование БВТС различными видами ИЛО представляет большой научный и практический интерес. Как правило, при воздействии различных видов ионного облучения наиболее значительные изменения наблюдаются в тонких поверхностных слоях материалов, что обусловливает необходимость использования поверхностно-чувствительных методов анализа. В настоящей работе исследовано влияние ионных пучков различной интенсивности и длительности на изменение морфологии поверхности, элементного и химического состава поверхностных слоев БВТС системы $\mathrm{TiC}-\mathrm{TiNi}$.

Для облучения образцов БВТС был использован непрерывный ионный пучок (НИП) $\mathrm{Ar}^{+}$с энергией ионов $20 \pm 1 \mathrm{keV}$ и флюенсом $\sim 10^{17} \mathrm{ion} / \mathrm{cm}^{2}$, a также импульсный ионный пучок (ИИП) состава $30 \% \mathrm{H}^{+}+70 \% \mathrm{C}^{+}$с энергией частиц $E \approx 250 \mathrm{keV}$, длительностью импульса $\sim 60 \mathrm{~ns}$, плотностью ионного тока $\sim 150 \mathrm{~A} / \mathrm{cm}^{2}$ и флюенсом $5 \cdot 10^{13} \mathrm{ion} / \mathrm{cm}^{2}$.

На рис. 1 представлены полученные с помощью растровой электронной микроскопии (РЭМ) изображения исходного образца БВТС состава 50\% TiC-50\% TiNi и образцов после различных видов ионного воздействия.
Облучение НИП приводит к образованию более развитого микрорельефа (рис. $1, b$ ), чем в случае исходного образца (рис. 1, $a$ ). Это обусловлено селективным распылением связующей фазы (TiNi) [2].

Воздействие ИИП (рис. 1,c) приводит к оплавлению поверхностного слоя и появлению в нем трещин вследствие генерации импульсных механических напряжений, обусловленных высоким градиентом температур и, возможно, ударной волны, возникающих в приповерхностном слое при таком воздействии $[1,3,4]$.

По данным энергодисперсионного анализа (ЭДА) во всех образцах присутствуют титан, никель, углерод и кислород (см. таблицу). Сравнение состава участков поверхности, отвечающих связующей фазе (никелиду титана), для исходного (точки 3,4 ) и облученного НИП (точки 4,5) образцов свидетельствует об окислении связующей фазы вследствие ионного модифицирования, что обусловлено нагревом при облучении до $\sim 300^{\circ} \mathrm{C}$. Для образца, облученного НИП, повышения концентрации кислорода на участках, отвечающих карбидным зернам (точки $1-3$ ), не происходит, что связано с более высокой температурой окисления ТiC.

В составе образца, облученного ИИП, наблюдается значительное снижение концентрации кислорода, что указывает на частичную термическую диссоциацию оксидов титана и никеля. Также наблюдается увеличение концентрации титана, что может быть обусловлено преимущественным испарением более летучего по сравнению с титаном никеля из интерметаллидной связ- 

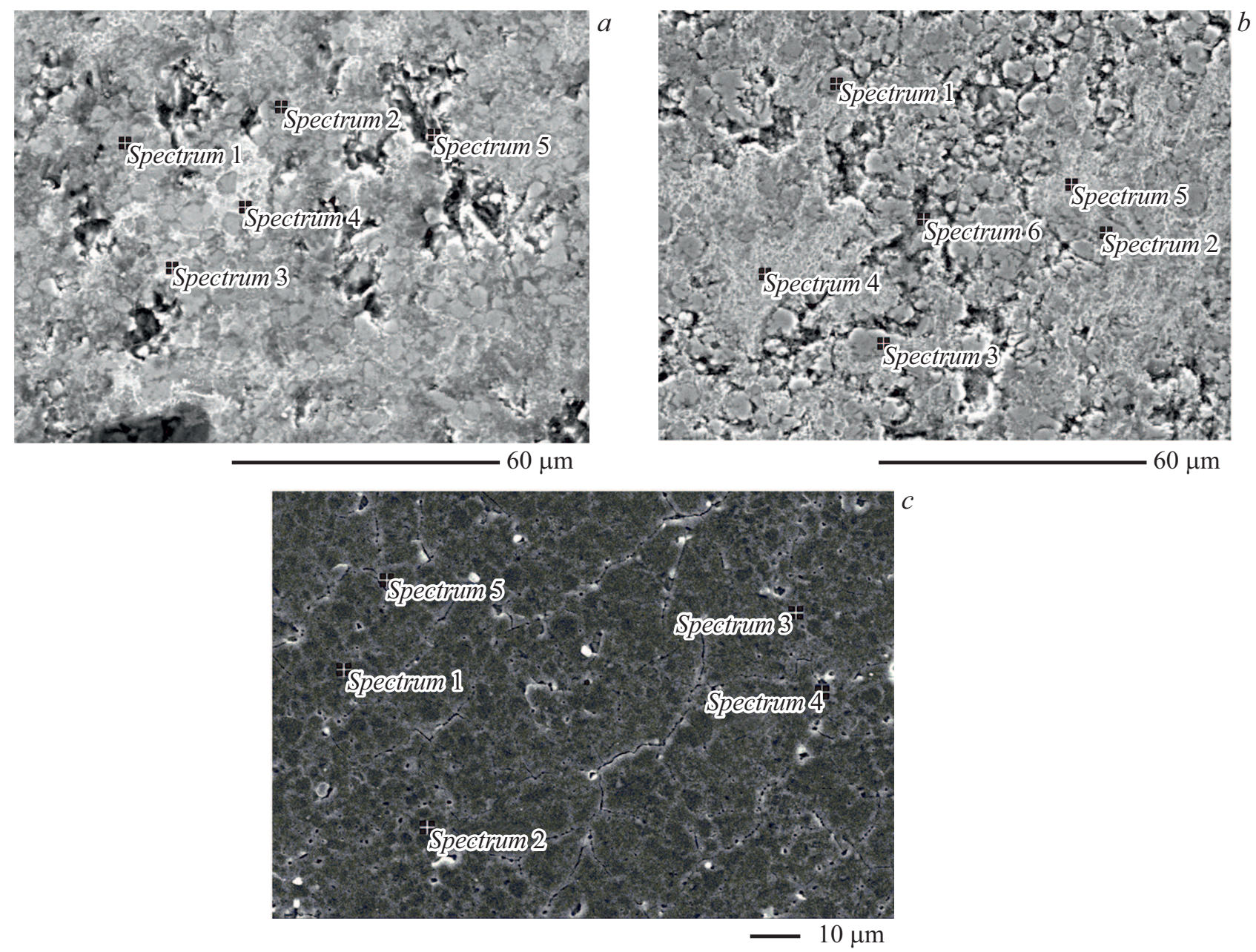

Рис. 1. РЭМ-изображения поверхности БВТС 50\% TiC-50\% TiNi в исходном образце $(a)$, после облучения непрерывным ионным пучком $(b)$ и импульсным ионным пучком $(c)$.

ки TiNi при воздействии ИИП. Сравнение отношений концентрации углерода и титана в точках, отвечающих преимущественно карбидным зернам (точки 1,5 для исходного образца, точки 2,4 для образца, облученного ИИП), свидетельствует о снижении содержания углерода в поверхностном слое карбидных зерен (см. таблицу). Вероятно, это обусловлено частичной диссоциацией связей Тi-C в поверхностном слое карбидных зерен вследствие высокоэнергетического воздействия ИИП [4].

Анализ химического состояния поверхностных слоев $(\sim 3 \mathrm{~nm})$ образцов был проведен с использованием метода рентгеновской фотоэлектронной спектроскопии (РФЭС). На рис. 2 представлены РФЭС Ті $2 p$-спектры твердого сплава после различных видов ионно-лучевой обработки. Спектр Ті $2 p$ является дублетом со спинорбитальным расщеплением $\sim 5.7 \mathrm{eV}$. Соотношение интенсивностей линий $2 p_{3 / 2}$ и $2 p_{1 / 2}$ составляет $2: 1$. При обсуждении спектров использовалось положение наиболее интенсивной линии дублета (Ti $\left.2 p_{3 / 2}\right)$. Согласно [5], положение максимума линии Тi $2 p_{3 / 2}$ для титана в металлическом состоянии составляет $454.1 \mathrm{eV}$, тогда как для оксида $\mathrm{TiO}_{2}-458.5 \mathrm{eV}$. Максимум линии $\mathrm{Ti} 2 p_{3 / 2}$ для карбидов титана лежит в диапазоне энергий связи $\sim 454.9-455.1 \mathrm{eV}$ [6]. Как видно (рис. 2, $a$ ), в спектре исходного образца максимум наиболее интенсивного компонента расположен при энергии связи $458.2 \mathrm{eV}$, что отвечает дефектному оксиду $\mathrm{TiO}_{2-x}$, наличие которого связано с естественным окислением поверхности твердого сплава. Максимум при энергии связи $454.1 \mathrm{eV}$ в спектре исходного твердого сплава отвечает состояниям титана, входящего в состав интерметаллидного соединения TiNi [7]. Также присутствует компонент с максимумом при энергии связи $\sim 455 \mathrm{eV}$, отвечающий карбиду титана.

После облучения непрерывным пучком в РФЭС-спектре Тi $2 p$ (рис. 2,b) положение основного максимума сдвигается в сторону высоких энергий связи к значению $458.5 \mathrm{eV}$, что указывает на окисление интерметаллидной связки с образованием высшего оксида $\mathrm{TiO}_{2}$. При этом компонент, отвечающий титану в составе $\mathrm{TiNi}$, в спектре отсутствует. Этот результат согласуется с данными ЭДА-анализа. Окисление связки 

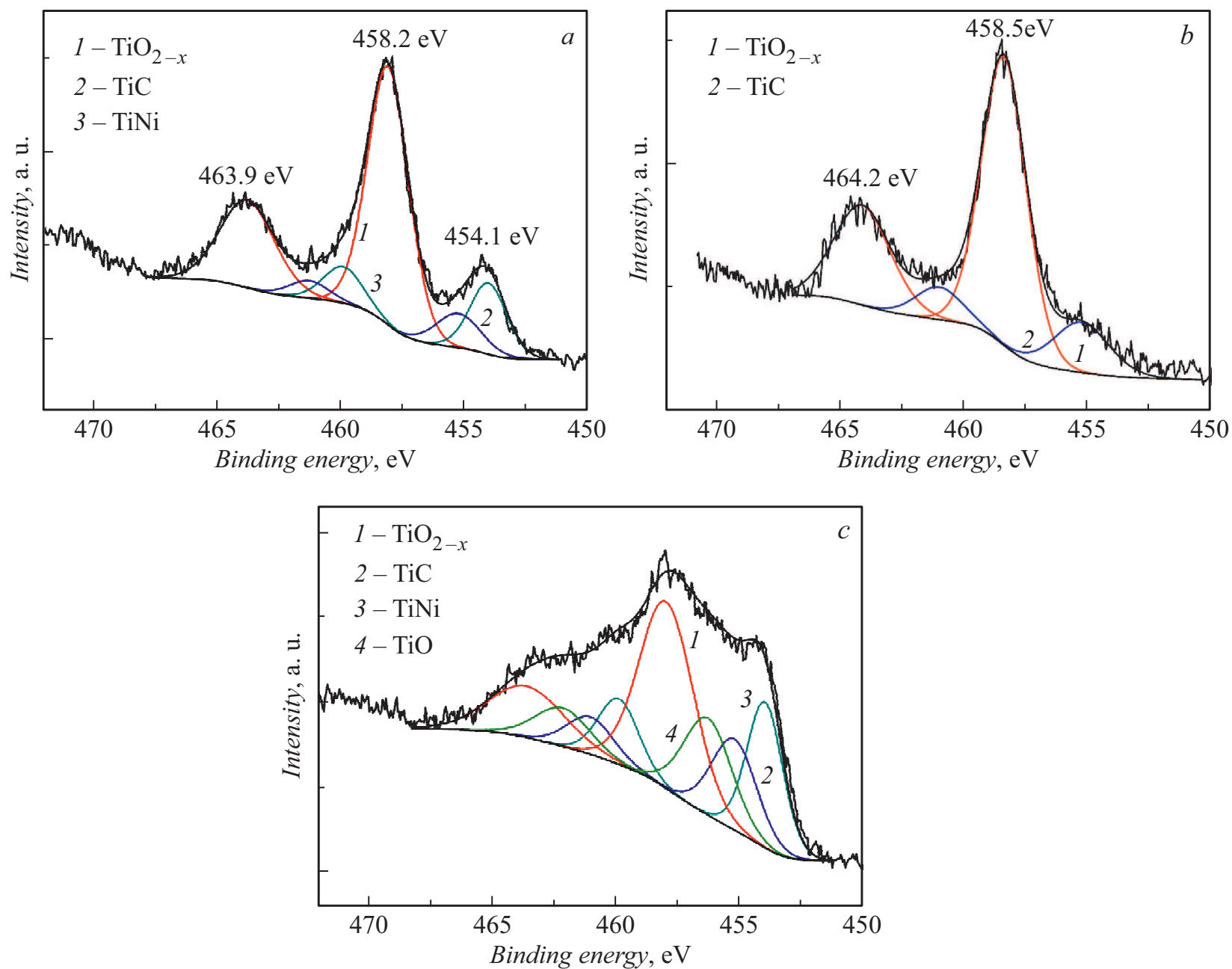

Рис. 2. РФЭС Тi $2 p$-спектры образца $50 \% \mathrm{TiC}-50 \%$ TiNi в исходном $(a)$, после облучения непрерывным ионным пучком $(b)$ и импульсным ионным пучком $(c)$.

предположительно может происходить в процессе облучения за счет взаимодействия разогретой под воздействием ионного пучка поверхности образца с кислородом остаточной атмосферы камеры ускорителя.

Спектр Ті $2 p$ образца твердого сплава после облучения ИИП (рис. 2,c) заметно отличается от спектра исходного образца. „Размытая“ форма спектра указывает на значительное повышение гетерогенности состава поверхности образца. Основной максимум спектра расположен при энергии связи $458.1 \mathrm{eV}$, что соответствует дефектному оксиду $\mathrm{TiO}_{2-x}$. В спектре присутствует также компонент с максимумом при энергии связи $456.4 \mathrm{eV}$, который отвечает состояниям титана в оксиде Ti(II) [8]. Частичное восстановление оксида титана хорошо согласуется с данными ЭДА-анализа. Кроме того, в спектре данного образца значительно возрастает интенсивность компонентов, отвечающих титану в составе TiNi, a также в составе карбида, что указывает на частичное восстановление интерметаллидной связки и образование карбидов (ТiC) в поверхностном слое при воздействии ИИП. При этом полученное по данным ЭДА сниже- ние количества углерода в составе карбидных зерен позволяет считать, что формирование ТiC протекает в интерметаллидной связке. Отсутствие свободного углерода в объеме образца позволяет говорить о том, что образование карбидов протекает с участием углерода, адсорбированного на поверхности образца вследствие его хранения, а также в процессе откачки в камере ионного ускорителя. Кроме того, в образовании новых связей Тi-C могут участвовать также атомы углерода, диффундирующие в связку вследствие диссоциации карбида титана в зернах.

Частичное восстановление $\mathrm{TiO}_{2}$ в составе поверхности образца, облученного ИИП, позволяет предположить протекание процесса карботермического восстановления, продуктами которого в зависимости от условий являются карбид титана и оксиды титана с меньшей степенью окисления, а также оксикарбиды титана $\left(\mathrm{TiO}_{x} \mathrm{C}_{1-x}\right)$ [9]. Температура протекания такой реакции в равновесных условиях $\left(\sim 1200-1600^{\circ} \mathrm{C}\right)$ значительно ниже температуры образования карбида титана вследствие взаимодействия металлического титана с углеро- 
Состав образцов (по данным ЭДА)

\begin{tabular}{|c|c|c|c|c|}
\hline \multirow{2}{*}{$\begin{array}{c}\text { Номер } \\
\text { точки }\end{array}$} & \multicolumn{4}{|c|}{ Концентрация, at.\% } \\
\hline & {$[\mathrm{C}]$} & {$[\mathrm{O}]$} & [Ti $]$ & {$[\mathrm{Ni}]$} \\
\hline \multicolumn{5}{|c|}{ Исходный образец } \\
\hline 1 & 31.96 & 26.81 & 40.25 & 0.98 \\
\hline 2 & 25.32 & 33.30 & 35.39 & 5.98 \\
\hline 3 & 28.58 & 14.84 & 16.96 & 39.62 \\
\hline 4 & 25.65 & 13.67 & 22.84 & 37.85 \\
\hline 5 & 26.02 & 34.45 & 38.02 & 1.50 \\
\hline \multicolumn{5}{|c|}{$\begin{array}{c}\text { Облучение непрерывным ионным } \\
\text { пучком }\end{array}$} \\
\hline 1 & 45.12 & 2.71 & 51.55 & 0.62 \\
\hline 2 & 36.65 & 19.04 & 43.17 & 1.14 \\
\hline 3 & 45.06 & 4.08 & 50.00 & 0.87 \\
\hline 4 & 14.02 & 34.15 & 16.47 & 35.35 \\
\hline 5 & 21.77 & 28.61 & 13.62 & 36.0 \\
\hline \multicolumn{5}{|c|}{$\begin{array}{c}\text { Облучение импульсным ионным } \\
\text { пучком }\end{array}$} \\
\hline 1 & 16.76 & 15.15 & 56.56 & 10.98 \\
\hline 2 & 30.43 & - & 68.19 & 1.38 \\
\hline 3 & 27.32 & - & 66.71 & 5.36 \\
\hline 4 & 33.28 & - & 65.59 & 1.13 \\
\hline 5 & 17.21 & 12.34 & 62.13 & 8.32 \\
\hline
\end{tabular}

дом $\left(\sim 2000^{\circ} \mathrm{C}\right)[9]$. В нашем случае наблюдаемое существенное оплавление поверхности после воздействия ИИП позволяет утверждать, что в процессе облучения температура на поверхности превышает температуру плавления оксида титана $\left(\sim 1800^{\circ} \mathrm{C}\right)$, преобладающего в поверхностном слое исходного образца согласно данным РФЭС.

Комплексное использование методов РЭМ, ЭДА и РФЭС впервые позволило оценить влияние непрерывного и импульсного облучения на морфологию и химическое состояние поверхности безвольфрамового твердого сплава $50 \% \mathrm{TiC}-50 \% \mathrm{TiNi}$. Показано, что непрерывный ионный пучок вызывает окисление дефектного оксида титана $\mathrm{TiO}_{2-x}$ до высшего оксида $\mathrm{TiO}_{2}$ в интерметаллидной связке $\mathrm{TiNi}$, в то время как ИИП приводит к частичной диссоциации связей $\mathrm{Ti}-\mathrm{C}$ в карбидных зернах твердого сплава. При этом в интерметаллидной связке наблюдается формирование карбидов титана и восстановление частично окисленного никелида титана. Сделано предположение, что формирование карбидов титана протекает с участием углерода, адсорбированного на поверхности образцов, а также углерода, диффундирующего в связку после частичной диссоциации связей Тi-C в карбидных зернах твердого сплава. Кроме того, при воздействии ИИП возможно также протекание процессов карботермического восстановления оксида титана с образованием карбидов и оксикарбидов титана.

Полученные в работе результаты могут быть использованы при разработке технологических процессов поверхностной модификации твердых сплавов на основе титана.

\section{Благодарности}

При выполнении исследований использовано оборудование Омского регионального центра коллективного пользования ОНЦ СО РАН.

\section{Конфликт интересов}

Авторы заявляют, что у них нет конфликта интересов.

\section{Список литературы}

[1] В.И. Бойко, А.Н. Валяев, А.Д. Погребняк, УФН, 169 (11), 1243 (1999).

[2] F.G. Zhang, X.P. Zhu, M.K. Lei, Surf. Coat. Technol., 206, 4146 (2012).

[3] М.Ю. Турищев, Ю.А. Тишанинов, О.В. Горожанкина, Вестн. Воронеж. гос. техн. ун-та, 14 (2), 138 (2017).

[4] X. Yu, J. Shen, M. Qu, H. Zhong, J. Zhang, Y. Zhang, S. Yan, G. Zhang, X. Zhang, X. Le, Nucl. Instrum. Meth. Phys. Res. B, 365, 225 (2015). DOI: 10.1016/j.nimb.2015.07.061

[5] D. Ramírez-Ortega, P. Acevedo-Peña, F. Tzompantzi, R. Arroyo, F. González, I. González, J. Mater. Sci., 52, 260 (2017). DOI: 10.1007/s10853-016-0328-3

[6] H. Cao, F. Qi, X. Ouyang, N. Zhao, Y. Zhou, B. Li, W. Luo, B. Liao, J. Luo, Materials, 11, 1742 (2018). DOI: $10.3390 / \mathrm{ma} 11091742$

[7] Y. Li, S. Wei, X. Cheng, T. Zhang, G. Cheng, Surf. Coat. Technol., 202, 3017 (2008). DOI: $10.1016 /$ j.surfcoat.2007.11.003

[8] T.B. Limbu, B. Chitara, D.J. Orlando, M.Y. Garcia Cervantes, S. Kumari, Q. Li, Y. Tang, F. Yan, J. Mater. Chem. C, 8, 4722 (2020). DOI: 10.1039/C9TC06984D

[9] A.R.M. Dewan, G. Zhang, O. Ostrovski, Met. Mater. Trans. B, 40, 62 (2009). DOI: 10.1007/s11663-008-9205-Z 